UDK 528.389

\title{
VERTIKALIŲJŲ IR HORIZONTALIŲJŲ ŽEMĖS PLUTOS JUDESIŲ SĄSAJOS
}

\author{
Algimantas Zakarevičius \\ Geodezijos ir kadastro katedra, Vilniaus Gedimino technikos universitetas, \\ Sauletekio al. 11, LT-10223 Vilnius-40, Lietuva, \\ el.paštas: Algimantas.Zakarevicius@ap.vtu.lt
}

Iteikta 20060220 , priimta 20060320

\begin{abstract}
Santrauka. Horizontalieji ir vertikalieji Žemès plutos judesiai tarpusavyje susiję, nes jie yra tụ pačiu Žemès plutą veikiančiu jègu pasekmè. Taip pat yra abipusis ryšys tarp Žemès plutos deformacijų ir tektoniniu itampu sklaidos. Todèl pagal išmatuotas vertikaliujų Žemès plutos deformacijų reikšmes galima ịvertinti horizontaliuju deformacijų rodiklius, nustatyti jų kaitos dèsningumus ir atvirkščiai. Straipsnyje pateikta nustatytoji analitinė sąsaja tarp horizontaliujų bei vertikaliujų Žemės plutos deformacijų. Sąsajoms nustatyti taikyta vektorinè bei tenzorinė analizė. Pateiktas algoritmas horizontaliujų Žemės plutos deformacijų rodikliams įvertinti pagal vertikaliujų judesių matavimo rezultatus. Deformacijų rodikliai įvertinti baigtinių elementų metodu. Pateiktas parengto algoritmo taikymo skaitinis pavyzdys.
\end{abstract}

Prasminiai žodžiai: Žemės plutos judesiai, tektoninės įtampos, deformacijų tenzorius, svarbiausios deformacijos.

\section{Ivadas}

Žemès pluta, veikiama giluminių tektoninių jègų, juda horizontaliaja ir vertikaliaja kryptimis. Kadangi horizontalieji ir vertikalieji Žemès plutos judesiai atsiranda dèl tų pačių priežasčių, jie tarpusavyje susiję. Giluminių jègų sukelti horizontalieji bei vertikalieji Žemès plutos judesiai turi ittakos geodinaminių ittampu persiskirstymui Žemès plutoje, t. y. atsiranda priežasties ir pasekmès grižtamieji ryšiai [1-4]. Todèl, tiriant geodeziniais metodais dabartinius Žemès plutos judesius, apie dabartinių Žemès plutos geodinaminių ittampu kryptingumą, jų sklaidą galima spręsti ne tik pagal horizontaliujų, bet ir vertikaliujų Žemès plutos judesių matavimus. Svarbiausios geodinaminių itampuc lauku kryptys sutampa su svarbiausiomis deformaciju kryptimis.

Šio darbo tikslas - nustatyti analitini ryši tarp vertikaliujų ir horizontaliujų Žemès plutos judesių bei parengti metodiką, kaip apskaičiuoti svarbiausiujų Žemès plutos horizontaliujuc deformacijų kryptis pagal vertikaliujų Žemès plutos deformacijų matavimu duomenis.

\section{Vertikaliụjų Žemès plutos judesių ir atstumų tarp} taškų pokyčių sąsajos

Sąsajoms atstumų tarp taškų Žemès paviršiuje pokyčių ir vertikaliuju judesių įvertinti taikysime baigtinių elementų metodą [5, 6]. Kaip baigtinius elementus pasirinksime trikampius. Erdvinei baigtinio elemento padéčiai nustatyti taikysime erdvinę stačiakampę topocentrinių horizontinių koordinačiu sistema, kurioje $X$ ašies kryptis sutampa su šiaurine per koordinačių pradžios tašką einančio dienovidinio projekcijos kryptimi. Tuomet vertikaliuju Žemès paviršiaus taškų poslinkių kryptis baigtinio elemento plote galima sutapatinti su $Z$ ašies kryptimi, horizontaliąsias deformacijas nagrinèti $X O Y$ plokštumoje, o atkarpų kryptis plokštumoje apibūdinti direkciniais kampais. Nagrinėdami santykines deformacijas, taikysime Legranžo deformacijų sampratą ir modeli [7]. Horizontaliujų ir vertikaliujų Žemès plutos judesių sąsajoms nustatyti taikysime vektorinį skaičiavimą.

Tarkime, kad turime geodeziniais ženklais vietovèje itvirtintą tam tikro dydžio trikampi $\mathrm{ABC}$, kuris erdvinèje stačiakampèje koordinačių sistemoje schemiškai parodytas paveiksle. Trikampio viršūnių padetis laiko momentu $T_{0}$ apibūdinama koordinatėmis: $A\left(X_{A}, Y_{A}, Z_{A}\right)$, $B\left(X_{B}, Y_{B}, Z_{B}\right), C\left(X_{C}, Y_{C}, Z_{C}\right)$. Laikome, kad per laiko tarpa $\Delta T=T-T_{0}$ trikampio viršūnių koordinatès $X, Y$ nepakito, o koordinate $Z$ dèl vertikaliujuc Žemès plutos judesių pakito reikšmėmis $\Delta Z_{A}, \Delta Z_{B}, \Delta Z_{C}$. Tuomet laiko momentu $T$ trikampio viršūnių koordinatès bus $A\left(X_{A}, Y_{A}, Z_{A}+\Delta Z_{A}\right), B\left(X_{B}, Y_{B}, Z_{B}+\Delta Z_{B}\right)$, $C\left(X_{C}, Y_{C}, Z_{C}+\Delta Z_{C}\right)$. 


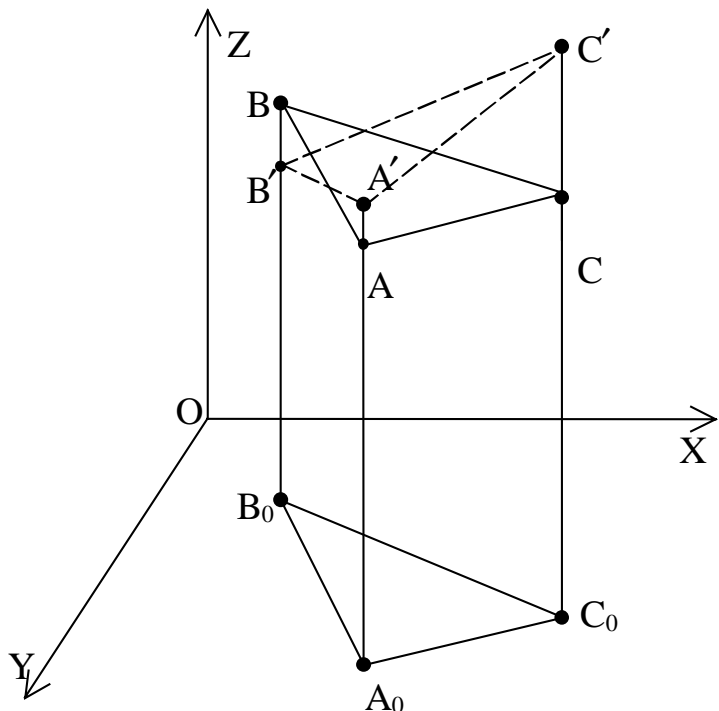

Trikampio deformacija: $\mathrm{ABC}$ - pradine trikampio forma, $\mathrm{A}^{\prime} \mathrm{B}^{\prime} \mathrm{C}^{\prime}-$ deformuotas trikampis, $\mathrm{A}_{0} \mathrm{~B}_{0} \mathrm{C}_{0}$ - trikampiu projekcija XOY plokštumoje

Deformation of triangle: $\mathrm{ABC}$ - initial shape of triangle, $\mathrm{A}^{\prime} \mathrm{B}^{\prime} \mathrm{C}^{\prime}-$ deformated triangle, $\mathrm{A}_{0} \mathrm{~B}_{0} \mathrm{C}_{0}$ - projection of triangles on the XOY plane

Laiko momentu $T_{0}$ vektoriaus $\overrightarrow{A B}$ modulis bus

$$
\begin{aligned}
& \overrightarrow{\mid A B} \mid=d_{A B}= \\
& \sqrt{\left(X_{B}-X_{A}\right)^{2}+\left(Y_{B}-Y_{A}\right)^{2}+\left(Z_{B}-Z_{A}\right)^{2}},
\end{aligned}
$$

o laiko momentu $T$ vektoriaus $\overrightarrow{A B}$ padètis pasikeis $\mathrm{i}$ $\overrightarrow{A^{\prime} B^{\prime}}$, ir jo modulis bus lygus

$$
\begin{aligned}
& \overrightarrow{A^{\prime} B^{\prime} \mid}=d_{A^{\prime} B^{\prime}}= \\
& \sqrt{\left(X_{B}-X_{A}\right)^{2}+\left(Y_{B}-Y_{A}\right)^{2}+\left[\left(Z_{B}+\Delta Z_{B}\right)-\left(Z_{A}+\Delta Z_{A}\right)\right]^{2}} .(2)
\end{aligned}
$$

Pakèlę (1) ir (2) lygybes kvadratu bei iš antrosios atèmę pirmają, gauname

$$
\begin{aligned}
& d_{A^{\prime} B^{\prime}}^{2}-d_{A B}^{2}=\left(\Delta Z_{B}-\Delta Z_{A}\right)^{2}+ \\
& 2\left(Z_{B}-Z_{A}\right)\left(\Delta Z_{B}-\Delta Z_{A}\right) .
\end{aligned}
$$

Galima parašyti, kad

$$
d_{A^{\prime} B^{\prime}}^{2}-d_{A B}^{2}=\left(d_{A^{\prime} B^{\prime}}-d_{A B}\right)\left(d_{A^{\prime} B^{\prime}}+d_{A B}\right) .
$$

Taikant Legranžo deformacijų modeli [6], iš (4) lygybès galima parašyti, kad

$$
d_{A^{\prime} B^{\prime}}^{2}-d_{A B}^{2}=\Delta d_{A B} 2 d_{A B},
$$

čia $\Delta d_{A B}=d_{A^{\prime} B^{\prime}}-d_{A B}$.
Tuomet iš (3) ir (5) lygybių gauname, kad santykinis trikampio kraštinès $\mathrm{AB}$ pailgejjimas per laiko tarpa $\Delta T=T-T_{0}$ dèl vertikaliujų Žemès plutos judesių yra

$$
\varepsilon_{A B}=\frac{\left(\Delta Z_{B}-\Delta Z_{A}\right)^{2}}{2 d_{A B}^{2}}+\frac{\left(Z_{B}-Z_{A}\right)\left(\Delta Z_{B}-\Delta Z_{A}\right)}{d_{A B}^{2}} .
$$

Analogiškai gauname

$$
\begin{aligned}
& \varepsilon_{A C}=\frac{\left(\Delta Z_{C}-\Delta Z_{A}\right)^{2}}{2 d_{A C}^{2}}+\frac{\left(Z_{C}-Z_{A}\right)\left(\Delta Z_{C}-\Delta Z_{A}\right)}{d_{A C}^{2}}, \\
& \varepsilon_{B C}=\frac{\left(\Delta Z_{C}-\Delta Z_{B}\right)^{2}}{2 d_{B C}^{2}}+\frac{\left(Z_{C}-Z_{B}\right)\left(\Delta Z_{C}-\Delta Z_{B}\right)}{d_{B C}^{2}}
\end{aligned}
$$

Iš (6-8) formulių, žinant trikampio viršūnèse vertikaliujų Žemès plutos judesių reikšmes $\Delta Z_{A}, \Delta Z_{B}, \Delta Z_{C}$, galima apskaičiuoti trikampio kraštinių $A B, A C$ ir $B C$ santykinius pailgèjimus, atsiradusius dèl vertikaliujų Žemés plutos judesių.

\section{Kampų deformacijos dėl vertikaliụjų Žemès plutos judesių}

Trikampio kampu pokyčiams, susidariusiems dèl vertikaliujų Žemès plutos judesių įtakos, nustatyti taikysime vektorių skaliarinès sandaugos savybes [8].

Pradiniu laiko momentu $T_{0}$ kampas $\varphi_{A}$ (pav.) yra

$$
\varphi_{A}=\arccos \frac{\overrightarrow{A B} \cdot \overrightarrow{A C}}{\overrightarrow{\mid A B}|\cdot| \overrightarrow{A C} \mid}
$$

čia $\overrightarrow{A B} \cdot \overrightarrow{A C}-$ skaliarinè vektorių sandauga, $|\overrightarrow{A B}|, \mid \overrightarrow{|A C|}-$ vektorių moduliai.

Laiko momentu $T$ dèl vertikaliujų judesių itakos pasikeitusi šio kampo reikšmė yra

$$
\varphi_{A^{\prime}}=\arccos \frac{\overrightarrow{A^{\prime} B^{\prime}} \cdot \overrightarrow{A^{\prime} C^{\prime}}}{\overrightarrow{A^{\prime} B^{\prime}}|\cdot| \overrightarrow{A^{\prime} C^{\prime}} \mid}
$$

Išreiškus atitinkamus vektorius projekcijomis $\mathfrak{i}$ koordinačių ašis pagal tų vektorių pradinių ir galinių taškų koordinates, (9) ir (10) lygčių skaliarinès sandaugos bus:

$$
\begin{aligned}
& \overrightarrow{A B} \cdot \overrightarrow{A C}=\left(X_{B}-X_{A}\right)\left(X_{C}-X_{A}\right)+ \\
& \left(Y_{B}-Y_{A}\right)\left(Y_{C}-Y_{A}\right)+\left(Z_{B}-Z_{A}\right)\left(Z_{C}-Z_{A}\right),
\end{aligned}
$$




$$
\begin{aligned}
& \overrightarrow{A^{\prime} B^{\prime}} \cdot \overrightarrow{A C}=\left(X_{B}-X_{A}\right)\left(X_{C}-X_{A}\right)+ \\
& \left(Y_{B}-Y_{A}\right)\left(Y_{C}-Y_{A}\right)+\left[\left(Z_{B}-Z_{A}\right)+\right. \\
& \left.\left(\Delta Z_{B}-\Delta Z_{A}\right)\right]\left[\left(Z_{C}-Z_{A}\right)+\left(\Delta Z_{C}-\Delta Z_{A}\right)\right] .
\end{aligned}
$$

Vektorių moduliai $\overrightarrow{\mid A B} \mid$ ir $\overrightarrow{\left|A^{\prime} B^{\prime}\right|}$ apskaičiuojami iš (1) ir (2) formulių. Analogiškai apskaičiuojami ir $|\overrightarrow{A C}|$ bei $\overrightarrow{\left|A^{\prime} C^{\prime}\right|}$ vektorių moduliai.

Kampo $\varphi_{A}$ pokytis per laikotarpi $\Delta T=T-T_{0}$ yra

$$
\Delta \varphi_{A}=\varphi_{A^{\prime}}-\varphi_{A} .
$$

Tokiu pačiu būdu apskaičiuojama

$$
\begin{aligned}
& \Delta \varphi_{B}=\varphi_{B^{\prime}}-\varphi_{B}, \\
& \Delta \varphi_{C}=\varphi_{C^{\prime}}-\varphi_{C} .
\end{aligned}
$$

Trikampio kampų pokyčių skaičiavimo kontrolè:

$$
\Delta \varphi_{A}+\Delta \varphi_{B}+\Delta \varphi_{C}=0
$$

\section{Trikampio ploto pokytis}

Trikampio ploto pokyčiui per laiko tarpą $\Delta T$ apskaičiuoti taikysime vektorinès sandaugos savybę [8], kad iš trikampio viršūnès išeinančių dviejų vektorių vektorinès sandaugos gautojo naujo vektoriaus modulis yra lygus dvigubam trikampio plotui.

Tuomet paveiksle parodytų trikampių viršūnes jungiančių vektorių projekcijas i koordinačių ašis apskaičiavus pagal viršūnių koordinates, atitinkamų vektorinių sandaugų vektoriai bus:

$$
\begin{aligned}
& \overrightarrow{A B} \times \overrightarrow{A C}=\left\{\begin{array}{ll}
\left(Y_{B}-Y_{A}\right) & \left(Z_{B}-Z_{A}\right) \\
\left(Y_{C}-Y_{A}\right) & \left(Z_{C}-Z_{A}\right)
\end{array} \mid,\right. \\
& \left.\left|\begin{array}{ll}
\left(Z_{B}-Z_{A}\right) & \left(X_{B}-X_{A}\right) \\
\left(Z_{C}-Z_{A}\right) & \left(X_{C}-X_{A}\right)
\end{array}\right|,\left|\begin{array}{ll}
\left(X_{B}-Y_{A}\right) & \left(Y_{B}-Y_{A}\right) \\
\left(X_{C}-X_{A}\right) & \left(Y_{C}-Y_{A}\right)
\end{array}\right|\right\},
\end{aligned}
$$

$\overrightarrow{A^{\prime} B^{\prime}} \times \overrightarrow{A^{\prime} C^{\prime}}=\left\{\begin{array}{l}\mid\left(Y_{B}-Y_{A}\right)\left[\left(Z_{B}-Z_{A}\right)+\left(\Delta Z_{B}-\Delta Z_{A}\right)\right] \\ \left(Y_{C}-Y_{A}\right)\left[\left(Z_{C}-Z_{A}\right)+\left(\Delta Z_{C}-\Delta Z_{A}\right)\right]\end{array}\right]$,

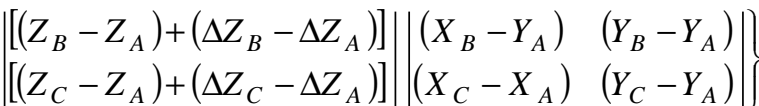

\section{čia $|\cdot|$-determinantai.}

Trikampio ploto santykinis pokytis (dilatacija) per laiko tarpą $\Delta T$ bus

$$
\varepsilon_{\Delta}=\frac{1}{2 P}\left[\overrightarrow{\mid A^{\prime} B^{\prime}}|\times| \overrightarrow{A^{\prime} C^{\prime}}|-\overrightarrow{A B}| \times|\overrightarrow{A C}|\right]
$$

čia $P$ - trikampio plotas, $\left|\overrightarrow{A^{\prime} B^{\prime}}\right| \times\left|\overrightarrow{A^{\prime} C^{\prime}}\right|,|\overrightarrow{A B}| \times|\overrightarrow{A C}|-$ vektoriu (17) ir (18) moduliai.

\section{Horizontaliųjų deformacijų rodiklių ivertinimas pagal vertikaliųjų judesių reikšmes}

Horizontaliujų Žemès plutos deformacijų baigtinio elemento plote rodikliai apibūdinami $[3,6]$ didžiausiuoju ir mažiausiuoju santykiniu pailgèjimais (jie vadinami svarbiausiomis deformacijų reikšmėmis):

$$
\left[\begin{array}{l}
D_{1} \\
D_{2}
\end{array}\right]=\frac{1}{2}\left[\left(e_{11}+e_{22}\right) \pm \sqrt{\left(e_{11}-e_{22}\right)^{2}+\left(e_{12}+e_{21}\right)^{2}}\right],
$$

didžiausiojo pailgejjimo kryptimi abscisių ašies atžvilgiu

$$
\varphi=\frac{1}{2} \operatorname{arctg}\left(-\frac{e_{12}+e_{21}}{e_{11}-e_{22}}\right)+\left[\begin{array}{c}
90^{\circ}, \text { kai }\left(e_{11}-e_{22}\right)>0 \\
0^{\circ} \text {, kai }\left(e_{11}-e_{22}\right)<0
\end{array}\right]
$$

bei baigtinio elemento dilatacija

$$
\varepsilon_{\Delta}=e_{11}+e_{22}
$$

čia $e_{i j}-$ horizontaliujų deformacijų antrosios eilès tenzoriaus komponentès [3].

Norint apskaičiuoti svarbiausiujų deformacijų rodiklius (20-21), būtina rasti būdų, kaip ịvertinti tenzoriaus komponentes pagal išmatuotų vertikaliujuc Žemès plutos judesių reikšmes.

Deformacijų tenzoriaus komponentèms pagal vertikaliujų judesių reikšmes apskaičiuoti galima panaudoti apskaičiuotus trikampio kraštinių pailgejjimus, kampų deformacijas bei dilataciją.

Žinoma [3], kad atkarpos, kurios direkcinis kampas $\alpha$, santykinis pailgèjimas

$$
\varepsilon_{\alpha}=e_{11} \sin ^{2} \alpha+e_{22} \cos ^{2} \alpha+\frac{1}{2}\left(e_{12}-e_{21}\right) \sin 2 \alpha .
$$

Turint apskaičiuotas trikampio kraštinių santykinių pailgejjimų reikšmes (6-8) ir pagal trikampio viršūniu koordinates apskaičiuotus trikampio kraštiniu direkcinius kampus, galima parašyti trijų lygčių sistemą:

$$
\left.\begin{array}{l}
e_{11} \sin ^{2} \alpha_{A B}+e_{22} \cos ^{2} \alpha_{A B}+ \\
\frac{1}{2}\left(e_{12}+e_{21}\right) \sin 2 \alpha_{A B}=\varepsilon_{A B} \\
e_{11} \sin ^{2} \alpha_{A C}+e_{22} \cos ^{2} \alpha_{A C}+ \\
\frac{1}{2}\left(e_{12}+e_{21}\right) \sin 2 \alpha_{A C}=\varepsilon_{A C} \\
e_{11} \sin ^{2} \alpha_{B C}+e_{22} \cos ^{2} \alpha_{B C}+ \\
\frac{1}{2}\left(e_{12}+e_{21}\right) \sin 2 \alpha_{B C}=\varepsilon_{B C}
\end{array}\right\}
$$


Išsprendus (24) lygčių sistemą, apskaičiuojama $e_{11}, e_{22}$ ir $\left(e_{12}+e_{21}\right)$ reikšmès. Turint šias reikšmes, galima apskaičiuoti svarbiausių deformacijų rodiklius (20-22).

Taip pat žinoma [3], kad kampų deformacijos

$$
\begin{aligned}
& \Delta \varphi=\frac{1}{2}\left(e_{11}-e_{22}\right)\left(\sin 2 \alpha_{d}-\sin 2 \alpha_{k}\right)+ \\
& \frac{1}{2}\left(e_{12}+e_{21}\right)\left(\cos 2 \alpha_{d}-\cos 2 \alpha_{k}\right),
\end{aligned}
$$

čia $\alpha_{d}, \alpha_{k}-$ kampo dešiniosios ir kairiosios krypties direkciniai kampai. Todèl deformacijų tenzoriaus komponentėms apskaičiuoti, turint pagal (9-15) formules apskaičiuotus kampų pokyčius, taikant (25) formulę galima sudaryti trijų lygčių sistemą. Tokią lygčių sistemą išsprendę, taip pat gautume $e_{11}, e_{22}$ ir $\left(e_{12}+e_{21}\right)$ reikšmes

(25) formulę galima taikyti ir iš (24) lygčiu sistemos apskaičiuotų tenzoriaus komponenčių kontrolei.

\section{Skaičiavimo pavyzdys}

Trikampio $\mathrm{ABC}$ viršūnių koordinatės:

$X_{A}=1000,000 \mathrm{~m}, Y_{A}=1000,000 \mathrm{~m}, Z_{A}=50,000 \mathrm{~m}$, $X_{B}=21000,000 \mathrm{~m}, Y_{B}=1000,000 \mathrm{~m}, Z_{B}=150,000 \mathrm{~m}$, $X_{C}=1000,000 \mathrm{~m}, Y_{C}=21000,000 \mathrm{~m}, Z_{C}=200,000 \mathrm{~m}$.

Taškų aukščiai per laiko tarpą $\Delta T=100$ metu pasikeitè:

$\Delta Z_{A}=-0,100 \mathrm{~m}, \Delta Z_{B}=0,200 \mathrm{~m}, \Delta Z_{C}=-0,200 \mathrm{~m}$.

Pagal koordinates apskaičiuoti kraštinių ilgiai:

$d_{A B}=20000,000 \mathrm{~m}, d_{A C}=20000,000 \mathrm{~m}$,

$d_{B C}=28284,271 \mathrm{~m}$.

Apskaičiuoti direkciniai kampai:

$\alpha_{A B}=0^{\circ}, \alpha_{A C}=90^{\circ}, \alpha_{B C}=135^{\circ}$.

Taikant (6-8) formules apskaičiuoti trikampio kraštinių santykiniai pailgejjimai: $\varepsilon_{A B}=7,5 \cdot 10^{-8}$, $\varepsilon_{A C}=-3,75 \cdot 10^{-8}, \varepsilon_{B C}=-1,9 \cdot 10^{-8}$.

Sudaroma (24) lygčiu sistema, kurią išsprendus gaunama: $e_{11}=-3,75 \cdot 10^{-8}, e_{22}=7,5 \cdot 10^{-8},\left(e_{12}+e_{21}\right)=$ $5,65 \cdot 10^{-8}$.

Taikant šias deformacijų tenzoriaus reikšmes, iš (20) lygties gaunama, kad kai $\Delta T=100$ metų, $D_{1}=8,2 \cdot 10^{-8}, \quad D_{2}=-4,4 \cdot 10^{-8}$. Vienerių metu laiko tarpo $D_{1}=8,2 \cdot 10^{-10}, D_{2}=-4,4 \cdot 10^{-10}$.

Didžiausiojo pailgejjimo $D_{1}$ kryptis (21) abscisių ašies atžvilgiu $\varphi=14^{\circ}$.

Dilatacija (22), kai $\Delta T=100$ metuc, $\varepsilon_{\Delta}=3,75 \cdot 10^{-8}$, o kai $\Delta T=1$ metai, $\varepsilon_{\Delta}=3,75 \cdot 10^{-10}$.

\section{Išvados}

1. Nustatytas analitinis ryšys tarp vertikaliuju ir horizontaliujų Žemès plutos judesių.
2. Parengtas algoritmas horizontaliujų Žemès plutos judesių svarbiausiuju deformacijų rodikliams ivvertinti pagal vertikaliujų Žemès plutos judesių matavimo rezultatus.

3. Taikant nustatytają horizontaliujuc ir vertikaliuju Žemès plutos judesių analitinę sąsają, galima, naudojant vertikaliujuc Žemès plutos judesių matavimo duomenis, kontroliuoti pagal išmatuotuosius horizontaliuosius poslinkius ivertintų svarbiausiuju Žemès plutos deformacijų rodiklių ir tektoninių itampu sklaidos dèsningumus.

4. Analitinę sąsają tarp vertikaliujų ir horizontaliuju Žemès plutos judesių galima taikyti ne tik tiriant dabartinius Žemès plutos judesius geodeziniais metodais, bet ir analizuojant geologinius duomenis, kai nagrinėjami ankstesnių geologinių periodų tektoniniai judesiai.

\section{Literatūra}

1. Tectonic structure of Lithuania. Compiled and edited by P. Suveizdis. Institute of Geology and Geography. Vilnius, 2003. 160 p. (in Lithuanian).

2. Šliaupa, S. Geodynamic evolution of the Baltic sedimentary basin. Habilitation thesis. Vilnius university, 2003. 206 p. (in Lithuanian).

3. Zakarevičius, A. Investigation of the recent geodynamic processes in the territory of Lithuania. Vilnius: Technika, 2003. 195 p. (in Lithuanian).

4. Esikov, N. Tectonophysical aspects of the analysis of recent movements of a terestrial surface. Novosibirsk: Nauka, 1979. 182 p. (in Russian).

5. Zienkiewicz, O. C.; Taylor, R. L. The finite element method. Vol 1, Fifth edition. Butterworth - Heinemann, $2000.689 \mathrm{p}$.

6. Zakarevičius, A.; Stanionis, A. Modelling the horizontal movements and deformations of the earth crust by the finite element method. Geodesy and Cartography (Geodezija ir kartografija), Vol XXX, No 2. Vilnius: Technika, 2004, p. 35-40 (in Lithuanian).

7. Atkočiūnas, J.; Nagevičius, J. Fundations of the theory of elasticity. Vilnius: Technika, 2000. 264 p. (in Lithuanian).

8. Korn, G. A.; Korn, T. M. Mathematical handbook for scientists and engineers. Moscow: Nauka, 1970. 720 p. (in Russian)

Algimantas ZAKAREVIČIUS. Doctor Habil, Professor. Dept of Geodesy and Cadastre, Vilnius Gediminas Technical University, Sauletekio al. 11, LT-10223 Vilnius-40, Lithuania $(\mathrm{Ph}+3705274$ 4701),

e-mail: Algimantas.Zakarevicius@ap.vtu.lt.

A graduate of Kaunas Polytechnic Institute (now Kaunas University of Technology), geodetic engineer, 1965. Doctor's degree at Vilnius University, 1973. Dr Habil degree at VGTU, 2000. Member of the Geodetic Commission of Estonia, Latvia and Lithuania. Research training at Geodetic Institute of Norwegian Mapping Authority, 1994. Author of over 130 publications and 3 monographs.

Research interests: investigations of the recent geodynamic processes, formation of geodetic networks. 